www.nature.com/ejhg

\title{
Molecular basis of hereditary pancreatitis
}

\author{
Jian-Min Chen and Claude Ferec \\ Centre de Biogénétique, University Hospital, EFS - Bretagne, Brest, France
}

\begin{abstract}
Hereditary pancreatitis (HP) is an autosomal dominant disease. Two heterozygous missense mutations, R122H (R117H) and N29I (N21I), in the cationic trypsinogen gene have been clearly associated with HP. The 'self-destruct' model proposed for the R122H mutation is discussed in connection with the existing theory of pancreatitis, and the basic biochemistry and physiology of trypsinogen, with particular reference to R122 as the primary autolysis site of the cationic trypsinogen. Two different genetic mechanisms are identified which cause the R122H mutation, and gene conversion is the likely cause of the N29I mutation. A unifying model, which highlights an indirect impairment on the R122 autolysis site is hypothesised for the N29I mutation. Possible predisposition to pancreatitis by additional DNA variants in the gene, such as the A16V signal peptide cleavage site mutation and the K23R activation peptide cleavage site mutation is suspected, but not proven. Evidence of genetic heterogeneity of HP is reviewed and cystic fibrosis transmembrane conductance regulator (CFTR) gene mutations detected in HP families are re-evaluated. Finally, large scale association studies are expected to clarify the additional variants' role in pancreatitis and to identify new HP genes. European Journal of Human Genetics (2000) 8, 473-479.
\end{abstract}

Keywords: pancreatitis; hereditary pancreatitis (HP); cationic trypsinogen gene; missense mutation; genetic heterogeneity; cystic fibrosis transmembrane conductance regulator (CFT); gene conversion; genetic predisposition; linkage analysis; association analysis

\section{Introduction}

Hereditary pancreatitis (HP; MIM 167800) is an autosomal dominant disease with approximately $80 \%$ penetrance and variable expression. ${ }^{1,2}$ Apart from an early age of onset and a positive family history, HP is indistinguishable from the sporadic disease. ${ }^{3,4}$ Although pancreatitis was hypothesised to result from inappropriate activation of pancreatic zymogens in $1896^{5}$ and the genetic nature of HP was identified in $1952,{ }^{6}$ the molecular basis of HP remained elusive until 1996, when a mutation in the cationic trypsinogen gene was demonstrated as being associated with $\mathrm{HP}^{7}$ While first touching on the major historical events in the pursuit of the etiology of HP briefly, this article focuses on the mutational spectrum of the cationic trypsinogen gene and the current understanding of the mechanisms underlying these muta-

Correspondence: Claude Ferec, MD, PhD, Centre de Biogénétique, University Hospital, EFS - Bretagne, 46 rue Félix Le Dantec, BP454, 29275 Brest Cedex, France. Tel: +33298445064; Fax: +332984305 55; E-mail: Claude.Ferec@univ-brest.fr

Received 26 November 1999; revised 2 March 2000; accepted 7 March 2000 tions. It then goes on to discuss the genetic heterogeneity of $\mathrm{HP}$ and finally re-evaluates the cystic fibrosis transmembrane conductance regulator (CFTR) gene mutations detected in HP families. It is suggested that the reader also refer to recent review papers ${ }^{8,9}$ to complement this article.

Mapping of one HP gene to chromosome 7q35 by genome-wide linkage analysis

The simple Mendelian model of inheritance of HP suggested that a single genetic defect might be responsible for this disorder. Historically, associations between pancreatitis and certain clinical variants have been reported but none of them substantiated (reviewed by Whitcomb et $\mathrm{al}^{10}$ ). Thus positional cloning, in which a disease gene is identified by virtue of its location in the genome rather than by knowledge of its biochemical defects, was carried out. Using a genome-wide gen etic linkage analysis, we mapped one HP gene to chromosome 7q35 in a large French HP family in $1996 .{ }^{11}$ Thislinkage was concurrently identified by Whitcomb et al ${ }^{10}$ and confirmed by Pandya et al. ${ }^{12}$ 


\section{Identification of the disease-causing gene expedited by the chance discovery of eight trypsinogen genes to be intercalated within the human $T$ cell receptor (TCR) $\beta$ locus on chromosome 7q35}

The next step was to identify the HP-causing gene that must be located somewhere within 7q35. Coincidentally, eight pancreatic trypsinogen genes were discovered intercalated within the human $\beta$ TCR locus in $7 q 35$ as a result of a large scale genomic sequencing effort. ${ }^{13}$ The complete genomic sequencing data of these trypsinogen genes enabled Whitcomb et $\mathrm{al}^{7}$ to easily exclude the pseudogenes and to design isoform-specific primers for accurately amplifying the two clearly functional cationic and anionic genes (see Chen and Ferec ${ }^{9}$ for details on the human trypsinogen family). Within months, an HP-associated mutation in the cationic trypsinogen gene was identified. ${ }^{7}$

\section{HP-associated mutations in the cationic trypsinogen gene}

A few words on the nomenclature for cationic trypsinogen mutations, which we discussed on a previous paper ${ }^{9}$ are appropriate at this point. Throughout this review the 'Recommendations for a Nomenclature System for Human Gene Mutations ${ }^{\prime 14}$ will be used, ie for amino-acid based systems, the codon for the initiator methionine is codon 1, with the 'comparative chymotrypsin numbering system' in parentheses the first time the mutations are mentioned in the text. To date, two missense mutations $\mathrm{R} 122 \mathrm{H}(\mathrm{R} 117 \mathrm{H})^{7}$ and $\mathrm{N} 29 \mathrm{l}$ $(\mathrm{N} 21 \mathrm{I})^{15}$ in the cationic trypsinogen have been unambiguously associated with HP.

\section{R122H (R117H)}

$\mathrm{R} 122 \mathrm{H}$, which results from a $\mathrm{G}>\mathrm{A}(\mathrm{CGC}>\mathrm{CAC})$ single nucleotide change in exon 3 of the cationic trypsinogen gene, is the first and most frequent mutation identified as being associated with HP. ${ }^{7,16-26}$ Whilst no one doubts its disease-causing role in $\mathrm{HP}$, some $\mathrm{e}^{27}$ do argue that 'self-destruct' mechanism proposed for $\mathrm{R} 122 \mathrm{H}^{7}$ has not yet been proven. In our opinion, however, this may be due to inadequate evaluation rather than a lack of good supporting data and, accordingly, we wish to highlight several issues.

On the one hand, trypsinogens are specifical ly activated in the intestine by enterokinase, and the newly formed trypsins are responsible for the activation of all other pancreatic digestive zymogens. ${ }^{28}$ Conceivably, premature activation of trypsinogens within the pancreas would be disastrous. Indeed, pancreatitis was proposed to be an autodigestive process more than 100 years ago, ${ }^{5}$ and intracellular premature activation of trypsinogen has been demonstrated to be an early event in both in vitro and three different in vivo models of pancreatitis. ${ }^{29}$ Although the 'co-localisation of trypsinogen with lysosomal hydrolases' in these models may not be relevant in HP, it is important to note that the human cationic trypsinogen possesses the ability to autoactivate, and that it autoactivates more easily than other trypsinogen isoforms. ${ }^{30}$ Furthermore, activated proteolytic enzymes such as trypsin and elastase can be detected within the pancreas in both clinical $^{31}$ and experimental ${ }^{32}$ forms of pancreatitis.

On the other hand, the body employs a series of protective mechanisms against premature zymogen activation. ${ }^{28}$ Of great importance is that trypsinogen/trypsin is subject to hydrolysis by trypsin itself. Most importantly, as in the case of the bovine $e^{33}$ and porcine ${ }^{34}$ trypsinogens, residue R122 of the human cationic trypsinogen was identified to be the primary autolysis site by co-sequencing of the first 14 residues of the partially proteolysed protein. ${ }^{35}$ Protection of this autolysis site by a monoclonal antibody against human cationic trypsinogen resulted in increased enzyme activity, ${ }^{35,36}$ and substitution of this site with certain amino acids, $^{37,38}$ especially histidine ${ }^{39}$ in the rat trypsinogen showed increased enzyme stability.

Thus, the pathogenesis of the $\mathrm{R} 122 \mathrm{H}$ mutation, considered in connection with the existing theory of pancreatitis, the basic biochemistry and physiology of trypsinogen, and combined with the molecular modelling and X-ray crystallography data provided in the original paper by Whitcomb et $\mathrm{al}^{7}$ is clear and evident. The R122H mutation would eliminate the R122 primary autolysis site, which clearly underlies the unique 'fail-safe' or 'self-destruct' mechanism against pancreatic autodigestion ${ }^{7}$ simply because histidine $(\mathrm{H})$ is not a trypsin cleavage site. Consequently, during excessive trypsinogen activation the stabilised mutant enzyme would trigger the pancreatic autodigestive process resulting in pancreatitis ${ }^{7,8}$ (Figure 1). What has yet to be proven is under what condition and in which subcellular compartment the premature activation of cationic trypsinogen is initiated.

Since R122 has been confirmed to be the primary autolysis site $^{35}$ and trypsin specifically catalyses the hydrolysis of peptide bonds on the carboxyl side of arginine (R) and lysine (K) residues, we surmise that in vitro experiments on the human $\mathrm{R} 122 \mathrm{H}$ mutant would not yield any more useful information beyond these fundamental observations. Transgenic models are attractive but certainly will be confounded by the existence of multiple functional trypsinogen genes and different protective mechanisms against trypsinogen activation in mice.

The $\mathrm{R} 122 \mathrm{H}$ mutation, in most cases, ${ }^{7,16-26}$ resulted from a single $\mathrm{G}>\mathrm{A}(\mathrm{CGC}>\mathrm{CAC})$ transition, which most probably occurred as a spontaneous deamination of 5-methylcytosine to give thymine in the CpG dinucleotides on the opposite strand. Interestingly, we identified a GC >AT (CGC >CAT) 2 bp nucleotide substitution, which also resulted in a R122H mutation but clearly arose via a different genetic mechanism - gene conversion. ${ }^{40}$ This theory was strongly supported by the presence of AT in the corresponding position of cationic trypsinogen's two homologous genes and a Chi-like sequence in the $3^{\prime}$ vicinity of the mutation. This genetic finding also 


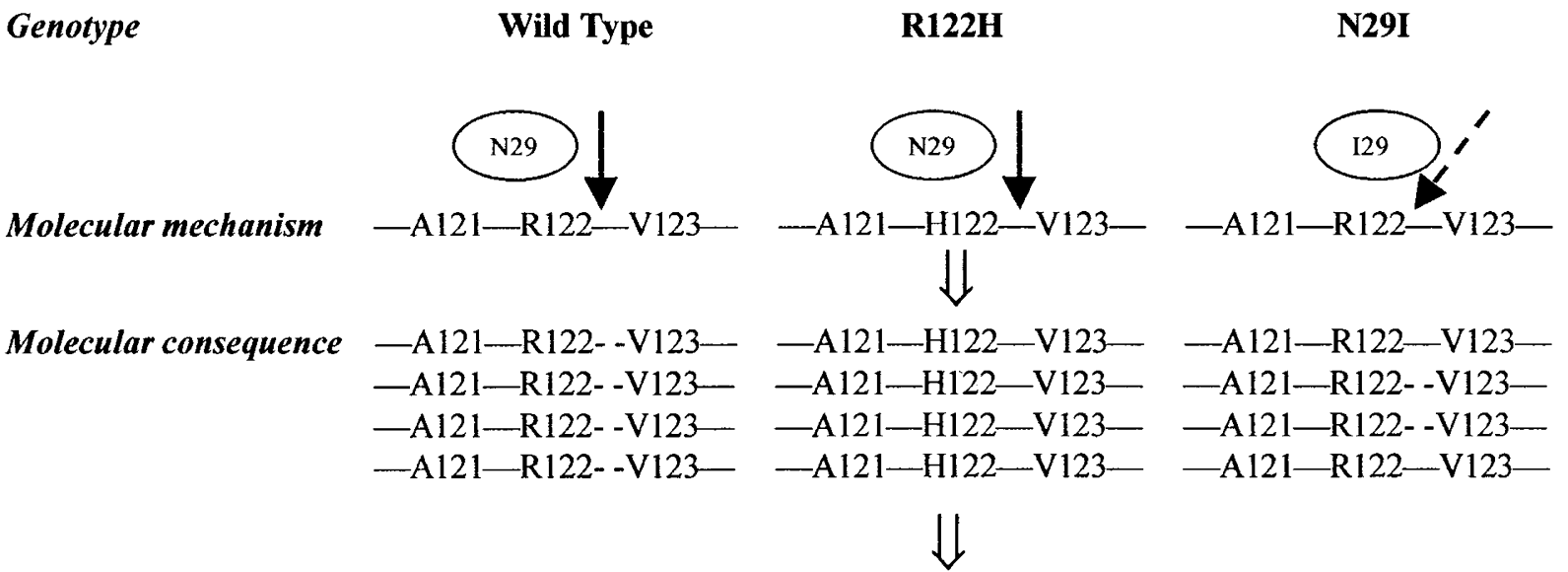

\section{Phenotype \\ Disease free \\ Severe form \\ Milder form}

Figure 1 A unifying model of the R122H and N29I mutations in the pathogenesis of HP. This model is based mainly on the observations that R122 is the primary autolysis site of the cationic trypsinogen, ${ }^{35}$ thereby constituting the unique 'self-destruct' defence system of the body against pancreatic autodigestion, ${ }^{7}$ and that N29 is near R122 on the trypsin surface. ${ }^{35}$ Arrows indicate the accessibility of trypsin-like enzymes to residue 122 . R122H is presumed to impair the 'self-destruct' defence system directly by abolishing the trypsin-like enzyme sensitive site R122; N29l is hypothesised to induce an as yet unknown conformational change, which in turn would hinder the accessibility of trypsin-like enzymes to R122 (indicated by the dashed arrow). As a result, unchecked mutant trypsin would initiate the activation cascade leading to pancreatic autodigestion and pancreatitis. However, N29I manifests a milder form of disease due to its 'indirect' impairment of the 'self-destruct' defence mechanism compared with R122H.

raises practical concerns. Since a single $G>A$ nucleotide change creates a novel Alf III site (A $\nabla$ CRYGT), the amplification of exon 3 followed by Alf III digestion ${ }^{7}$ has been widely adopted to screen for the R122H mutation. ${ }^{16-19,21}$ Obviously, if $\mathrm{R} 122 \mathrm{H}$ mutation arose as a result of a gene conversion event, it would not be detected by this simple method. ${ }^{40}$

\section{N29l (N21I)}

Whilst the $\mathrm{R} 122 \mathrm{H}$ has been demonstrated to be the most frequent mutation in $\mathrm{HP}$, another missense mutation named $\mathrm{N} 29$, which results from a single $\mathrm{A}>\mathrm{T}$ (AAC >ATC) nucleotide substitution in exon 2 of the cationic trypsinogen gene, also turns out to be present worldwide. ${ }^{15,20-22,25}$ However, unlike R122, N29 is clearly not a trypsin cleavage site and thus could not be readily explained by the 'self-destruct' mechanism. Some authors ${ }^{20}$ have even questioned whether the N29l mutation could alter the molecular nature of the enzyme dramatically enough to produce pancreatitis, based mainly on the observation that the first $38 \mathrm{~N}$-terminal amino acids of the secreted form of cationic trypsinogen containing this mutation happen to be identical with that of the native anionic trypsinogen isoform (Figure 2). It is this observation that attracted our attention and prompted us to provide an explanation for N29I's origin in the context of the trypsinogen family and based on this, unify the available knowledge to highlight an indirect 'self-destruct' model for the N29I.

Strong evidence suggested that $\mathrm{N} 29 \mathrm{I}$ arose from a gene conversion event in which the wild-type functional anionic trypsinogen gene acted as the donor sequence and, more importantly, N29 and 129 might represent rare mutations of the two functional human trypsinogen genes, positively selected by evolution to somehow endow an as yet unknown advantageous effect on their respective protein's structure and function. ${ }^{41}$ Thus, a rare, non-reciprocal genetic information exchange between the anionic and the cationic trypsinogen genes at this position could be disastrous. In support of this, the physico-chemical characteristics of Ile are quite different from those of Asn, and a structural difference for

$$
\begin{aligned}
& \begin{array}{llllllll}
1 & 11 & 16 & 23 & 29 & 31 & 41 & 51
\end{array} \\
& \text { CT MNPLLILTEV AAALAAPFDD DDRIVGGYNC EENSVPYQVS LNSGYHECGG SLINEQWVVS }
\end{aligned}
$$

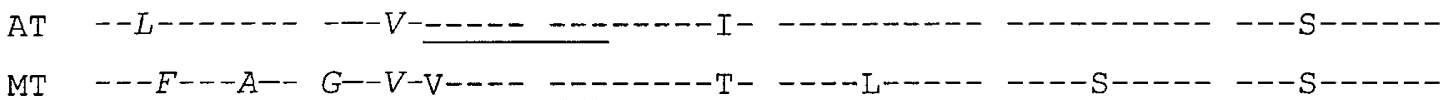

Figure 2 Partial alignment of the deduced amino acid sequences of cationic (CT), anionic (AT), and meso (MT) pretrypsinogens. Numbering of amino acids begins at the ATG initiator codon. Dashes indicate identity with the CT sequence. Signal peptides are in italics, activation peptides are underlined, and residues with mutations are in bold. Note the presence of Val at residue 16 of the premesotrypsinogen and the presence of lle at residue 29 of the anionic pretrypsinogen, and the interesting locations of A16 and K23 in the CT sequence. Also compare the CT sequence containing N29I with AT. 
this substitution has been suggested by the different affinity constants of a monoclonal antibody towards the human anionic and cationic trypsinogen isoforms. ${ }^{35,36} \mathrm{~A}$ computer analysis of the $\mathrm{N} 29$ I substitution in the cationic trypsinogen protein also predicted a secondary structural change from a native 'turn' into a 'sheet' in the flanking region. ${ }^{20}$

The next pertinent question is how this gene conversionlike event could produce pancreatitis. Considering the facts that $\mathrm{N} 29$ I is a disease-causing mutation in HP, that HP is a 'gain-of-function' disorder, that the N29l does not seem to affect either the intracel lular transportation or the autoactivation of the protein, and that N29 is near R122 on the surface of trypsin, ${ }^{35}$ we believe that N29l must somehow exert an indirect impairment on the R122 autolysis site., ${ }^{9,42}$ This is given strong support by the recent molecular modelling data. An electrostatic bond at E32-R122, presumably induced by the N29l substitution, would hinder the accessibility of trypsin-like enzymes to the R122 autolysis site. ${ }^{8}$ In addition, recent in vitro mutagenesis experiments have shown that N29I mutants in the rat ${ }^{43}$ and human ${ }^{44}$ trypsinogens demonstrate increased enzyme stability. This indirect model could further reconcile the clinical observations that $\mathrm{N} 29$ l causes a milder form of HP in terms of a relatively later age of disease onset and fewer hospitalisations compared with $\mathrm{R} 122 \mathrm{H}^{15,20}$ (Figure 1).

\section{Novel DNA variants identified in cationic trypsinogen gene in sporadic pancreatitis}

The nature of HP as an autosomal dominant disorder implies that the variety or number of causal mutations in the cationic trypsinogen gene will be limited, since 'lossof-function' mutations would not cause the disease. This holds true in the context of HP in which only the R122H and $\mathrm{N} 29$ I are associated. However, large scale mutational screening efforts in sporadic disease revealed new DNA variants, some of which may predispose someone to pancreatitis. Due to the scarcity of data about these DNA variants, this section is not meant to give any definitive conclusions but rather intends to initiate discussions.

\section{A16V}

Witt et $\mathrm{al}^{26}$ first described a strong association between a novel DNA variant named A16V with chronic pancreatitis. In their study, four out of 44 children and adolescents with chronic pancreatitis were found to carry the A16V variant. We independently identified this variant in two out of 312 patients with the sporadic disease. ${ }^{45}$

In contrast to the $80 \%$ penetrance of the $\mathrm{R} 122 \mathrm{H}$ and N29I mutations, the penetrance of A16V is clearly low - only one of the seven first-degree relatives carrying the A16V mutation in Witt et al's report was affected, and neither of the two A16V carriers in our study had a family history of pancreatitis. Even more interestingly, as an lle is present at residue 29 of the functional anionic pretrypsinogen, a Val is present at residue 16 of the functional premesotrypsinogen (Figure2). However, whilst a N29I mutation results in a nonconservative amino acid substitution, which is considered to be important in causing the disease, ${ }^{42}$ an A16V mutation results in a conservative substitution, which may underlie its lower penetrance. ${ }^{46}$

Since A16 happens to be the signal peptide cleavage site (Figure2), the A16V substitution was suggested to cause a 'loss' rather than a 'gain' of trypsin function in a recent discussion. ${ }^{47}$ We disagree with this assumption due to two interrelated considerations. First, A16V seems to be associated with pancreatitis. Second, a 'loss of function' of the cationic trypsinogen could not cause the disease. Alternatively, we argue that an A16V substitution would most likely disrupt the intracellular transportation of the pretrypsinogen and, in this vein, it may even be tempting to speculate that this substitution could lead to the co-localisation of pretrypsinogen with lysosomal hydrolases, the very well documented trypsinogen activation mechanism in animal models of pancreatitis. ${ }^{29,46}$

\section{K23R}

The K23R variant was only detected in two affected members of one family and was not present in 400 control chromosomes. $^{22}$ Unfortunately, no other family members were available for segregation analysis. Since K23 is the last residue of the highly conserved eight amino acid activation peptide of trypsinogens (Figure2), a substitution could be expected to have an effect on phenotype, ie to enhance autoactivation. However, the fact that the physico-chemical properties between $K$ and $R$ are quite similar, that an $R$ is used in the corresponding position of rat trypsinogen $V^{48}$ and that $R$ is also cleaved by trypsin suggests a neutral effect.

\section{V123M}

This variant was detected in a single case with sporadic disease and was not present in 400 control chromosomes (JM Chen et al in preparation). Could it affect the R122 autolysis site (Figure1)?

\section{Other variants}

In addition to the above three interesting DNA variants, further missense mutations have been identified separately in single cases. ${ }^{45}$ Among them, the P36R and G83E resulted in non-conservative amino acid substitutions at well conserved residues. The fact that frameshift, nonsense and splicing mutations were never detected is consistent with a 'gain-of-function' disease.

\section{Genetic heterogeneity of HP}

Mutations in the cationic trypsinogen gene do not appear to be the whole story and, in hindsight, Sarles et al's report that $\mathrm{HP}$ is a group of at least two diseases having a similar clinical picture and pathological features but with different chemical 
compositions of calculi (protein lithiasis vs calcic lithiasis) presented in pancreatic duct ${ }^{49}$ may have suggested genetic heterogeneity. Nevertheless, definite proof was first provided by Dasouki et $\mathrm{al}^{17}$ in 1998. Two of eight American HP families were found not to carry the R122H mutation. Although they did not analyse the N29l mutation in their patients, the involvement of this mutation and other possible mutations, if there are any, in the cationic trypsinogen gene was ruled out by the negative linkage between the disease and the loci D7S661 and D7S676 in at least one family. We provided further evidence in French HP families and, especially, a segregation analysis using 7q35 markers in family $\mathrm{N}$ indicated that the affected $I 12$ and $I 13$ inherited different haplotypes from II, and III 2 did not receive II's haplotype, ${ }^{22}$ excluding not only the cationic trypsinogen gene, but also all the other genes on chromosome 7. There are additional studies supporting genetic heterogeneity ${ }^{20,25,26}$ and a preliminary report suggests that a new HP gene may be located on chromosome $12 .{ }^{50}$ However, the observed linkage with a lod score $<3.0$ needs further confirmation. Additionally, possible involvement of anionic trypsinogen gene on chromosome7, mesotrypsinogen gene on chromosome $9,{ }^{51}$ pancreatic secretory trypsin inhibitor gene on chromosome $5^{52}$ and pancreatitis-associated protein gene on chromosome $2^{53}$ in HP has been excluded by candidate gene approach .

\section{Is CFTR a new HP gene?}

It is worth pointing out that in 1996, the same year the identification of the cationic trypsinogen gene was associated with HP, mutations in the CFTR gene were reported to be detected in HP families. ${ }^{54}$ Of the two new mutations identified, a heterozygous L327R was found to segregate with the disease in one family. The possibility that this family might be, in fact, a CF family was excluded by the normal sweat chloride levels, normal sputum cultures, forced vital capacity (FVC) and forced expiratory volume (FEV) values over $100 \%$ and no family history of CF. ${ }^{54}$

To date, there have been no further reports describing CFTR gene mutations in HP families. Our haplotype analysis in family $\mathrm{N}^{22}$ definitively excluded the involvement of the CFTR gene due to its location on chromosome7, and the potential linkage of a new HP gene was to chromosome 12 in another American family. ${ }^{50}$ However, two simultaneous articles reported an association between sporadic chronic pancreatitis and mutations in the CFTR gene. ${ }^{55,56}$ In these two studies, none of the patients carrying CFTR mutations had the combination of sinopulmonary disease, high sweat electrolyte concentrations, and low nasal potential-difference values that are diagnostic of CF, and the vast majority of these patients had mutations in only one copy of the CFTR gene. Analogous with other atypical diseases of CF, including congenital absence of the vas deferens, chronic bronchitis and sinusitis with nasal polyposis, sporadic chronic pan- creatitis with abnormal CFTR alleles was referred to as a monosymptomatic form of CF. ${ }^{57}$

These observations prompted us to re-evaluate the role of the L327R missense mutation in the CFTR gene identified in a single HP family. ${ }^{54}$ There could be three explanations: first, this substitution is indeed a disease-causing mutation. If this were the case, this family may be more adequately diagnosed as having monosymptomatic pancreatitis of CF. Second, the L327R substitution represents a mere coincidence, provided that it does not have any phenotype-modifying effect on the disease. Thus, the real disease-causing mutation, probably a cationic trypsinogen mutation in this family, remains to be identified. Third, it is tempting to speculate that CFTR may act as a modifier gene in the pathogenesis of $\mathrm{HP}$, and more work is warranted to explore this possibility.

\section{Conclusions}

The identification of mutations in the cationic trypsinogen gene as the molecular basis for most cases of HP confirmed for the first time the existing theory of pancreatitis as an autodigestive disease and marked the beginning of a new era in pancreatic research. This finding also demonstrates how genetic investigation can provide insights into protein structure and function. Furthermore, if N29I indeed arose as a gene conversion event, it would represent the first example of such an event occurring between two functional wild-type genes which resulted in a disease. However, as we have discussed, several issues remain to be resolved.

First, more extensive association studies are needed to correlate the clinical features of pancreatitis (phenotype) with the different cationic trypsinogen missense mutations (genotype), particularly those rare DNA variants detected in sporadic disease. At present, the possibility that slight variations in the primary structure of the cationic trypsinogen induced by these variants may render a degree of predisposition to pancreatic autodigestion cannot be excluded. Second, the identification of another HP gene promises to not only provide further insights into the molecular pathogenesis of $\mathrm{HP}$, but also better means for diagnosis, family testing and treatment. Based on the patchy, focal nature of pancreatitis and the examples of the cationic trypsinogen and CFTR gene mutations, the new HP gene is expected to result in a defect in either the acinar or ductal cells of the exocrine pancreas. Since the remaining HP families are generally small, we envision that association studies, fuelled by the approaching availability of the entire human genome sequence and the increasing number of single nucleotide polymorphisms (SNPs), will play an important role in this enduring effort. Finally, the co-examination of CFTR and cationic trypsinogen gene mutations in pancreatitis subjects would shed light on gene-gene interaction in the disease process. Hopefully, answers to these questions may come sooner through the co-operative effort of the two major study groups for HP - the Midwest Multicenter 
Pancreatic Study Group in North America (website: http:/ /www.pitt.edu/ whitcomb/HPRN/) and the EUROPAC Registry of Hereditary Pancreatic Disease in the UK and Europe (website: http://www.liv.ac.uk/surgery/europac/html).

\section{Acknowledgements}

We appreciate the comments of Jean-Charles Dagorn (U.315 INSERM, Marseille, France) on a draft of this manuscript. This work was supported by the INSERM (CRI 96-07). JMC is a guest research scientist of the INSERM.

\section{References}

1 Le Bodic L, Schnee M, Georgelin T et al: An exceptional genealogy for hereditary chronic pancreatitis. Dig Dis Sci 1996; 41: 1504-1510.

2 Sossenheimer MJ, Aston CE, Preston RA et al: Clinical characteristics of hereditary pancreatitis in a large family, based on highrisk haplotype. Am J Gastroenterol 1997; 92: 1113-1116.

3 Konzen KM, Perrault J, Moir C, Zinsmeister AR: Long-term followup of young patients with chronic hereditary or idiopathic pancreatitis. Mayo Clin Proc 1993; 68: 449-453.

4 Paolini $O$, Hastier $P$, Buckley $M$ et al: The natural history of hereditary chronic pancreatitis: a study of 12 cases compared to chronic alcoholic pancreatitis. Pancreas 1998; 17: 266-271.

5 Chiari H: Ueber Selbstverdauung des menschilichen pankreas. Z Heilkunde 1896; 17: 69-96.

6 Comfort MW, Steinberg AG: Pedigree of a family with hereditary chronic relapsing pancreatitis. Gastroenterology 1952; 21: 54-63.

7 Whitcomb DC, Gorry MC, Preston RA et al: Hereditary pancreatitis is caused by a mutation in the cationic trypsinogen gene. Nat Genet 1996; 14: 141-145.

8 Whitcomb DC: Hereditary pancreatitis: new insights into acute and chronic pancreatitis. Gut 1999; 45: 317-322.

9 Chen JM, Ferec C: Genes, cloned CDNAs' and proteins of human trypsinogens and pancreatitis-associated cationic trypsinogen mutations. Pancreas 2000; (in press).

10 Whitcomb DC, Preston RA, Aston CE et al: A gene for hereditary pancreatitis maps to chromosome7q35. Gastroenterology 1996; 110: $1975-1980$.

11 Le Bodic L, Bignon JD, Raguenes $O$ et al: The hereditary pancreatitis gene maps to long arm of chromosome7. Hum $\mathrm{Mol}$ Genet 1996; 5: 549-554.

12 Pandya A, Blanton SH, Landa B et al: Linkage studies in a large kindred with hereditary pancreatitis confirms mapping of the gene to a 16-cM region on 7q. Genomics 1996; 38: 227-230.

13 Rowen L, Koop BF, Hood L: The complete 685-kilobase DNA sequence of the human $\beta$ T cell receptor locus. Science 1996; 272: 1755-1762.

14 Antonarakis SE, the Nomenclature Working Group: Recommendations for a nomenclature system for human gene mutations. Hum Mutat 1998; 11: 1-3.

15 Gorry MC, Gabbaizedeh D, Furey W et al: Mutations in the cationic trypsinogen gene are associated with recurrent acute and chronic pancreatitis. Gastroenterology 1997; 113: 1063-1068.

16 Gress TM, Micha AE, Lacher U, Adler G: Diagnosis of a "hereditary pancreatitis" by the detection of a mutation in the cationic trypsinogen gene. Dtsch Med Wochenschr 1998; 123: 453-456.

17 Dasouki MJ, Cogan J, Summar ML et al: Heterogeneity in hereditary pancreatitis. Am J Med Genet 1998; 77: 47-53.

18 Elitsur Y, Chertow BC, Jewell RD, Finver SN, Primerano DA: Identification of a hereditary pancreatitis mutation in four West Virginia families. Pediatr Res 1998; 44: 927-930.

19 Bell SM, Bennett C, Markham AF, Lench NJ: Evidence for a common mutation in hereditary pancreatitis. Mol Pathol 1998; 51: 115-117.
20 Nishimori I, Kamakura M, Fujikawa-Adachi $\mathrm{K}$ et al: Mutations in exons 2 and 3 of the cationic trypsinogen gene in Japanese families with hereditary pancreatitis. Gut 1999; 44: 259-263.

21 Teich N, Mossner J, Keim V: Screening for mutations of the cationic trypsinogen gene: are they of relevance in chronic alcoholic pancreatitis? Gut 1999; 44: 413-416.

22 Ferec $\mathrm{C}$, Raguenes $\mathrm{O}$, Salomon R et al: Mutations in the cationic trypsinogen gene and evidence for genetic heterogeneity in hereditary pancreatitis. J Med Genet 1999; 36: 228-232.

23 Weber P, Keim V, Zimmer KP: Hereditary pancreatitis and mutation of the trypsinogen gene. Arch Dis Child 1999; 80: 473-474.

24 Pandya A, Xia XJ, Blanton SH, Landa B, Markello T, Nance WE: Implications of molecular diagnostic testing in families with hereditary pancreatitis. Genet Test 1997-98; 1: 207-211.

25 Creighton J, Lyall R, Wilson DI, Curtis A, Charnley R: Mutations of the cationic trypsinogen gene in patients with chronic pancreatitis. Lancet 1999; 354: 42-43.

26 Witt H, Luck W, Becker M: A signal peptide cleavage site mutation in the cationic trypsinogen gene is strongly associated with chronic pancreatitis. Gastroenterology 1999; 117: 7-10.

27 Teich N, Hoffmeister A, Keim V: Mutations of cationic trypsinogen in chronic pancreatitis. Lancet 1999; 354: 1302.

28 Rinderknecht $\mathrm{H}$ : Activation of pancreatic zymogens. Normal activation, premature intrapancreatic activation, protective mechanisms against inappropriate activation. Dig Dis Sci 1986; 31: 314-321.

29 Steer ML: The early intraacinar cell events which occur during acute pancreatitis [Frank Brooks memorial lecture]. Pancreas 1998; 17: 31-37.

30 Colomb E, Figarella C, Guy O: The two human trypsinogens. Evidence of complex formation with basic pancreatic trypsin inhibitor-proteolytic activity. Biochim Biophys Acta 1979; 570: 397-405.

31 Geokas MC, Rinderknecht H: Free proteolytic enzymes in pancreatic juice of patients with acute pancreatitis. Am J Dig Dis 1974; 19: 591-598.

32 Yamaguchi H, Kimura T, Mimura K, Nawata H: Activation of proteases in cerulein-induced pancreatitis. Pancreas 1989; 4: 565-571.

33 Maroux S, Rovery M, Desnuelle P: An autolyzed and still active form of bovine trypsin. Biochim Biophys Acta 1967; 140: 377-380.

$34 \mathrm{Ru}$ BG, Du JZ, Zeng YH et al: Active products of porcine trypsin after autolysis. Sci Sin 1980; 23: 1453-1460.

35 Gaboriaud C, Serre L, Guy-Crotte O, Forest E, Fontecilla-Campus JC: Crystal structure of human trypsin 1: unexpected phosphorylation of Tyr151. J Mol Biol 1996; 259: 995-1010.

36 Guy-Crotte O, Miszczuk-Jamska B, Brayle A, Lafont P, Figarella C: Monoclonal antibodies to human pancreatic trypsin 1 inhibit the activation of human trypsinogens 1 and 2. Eur J Biochem 1992; 204: 133-136.

37 Varallyay E, Pal G, Patthy A, Szilagyi L, Graf L: Two mutations in rat trypsin confer resistance against autolysis. Biochem Biophys Res Commun 1998; 243: 56-60.

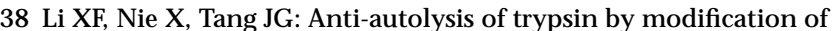
autolytic site Arg117. Biochem Biophys Res Commun 1998; 250: 235-239.

39 Sahin-Toth M, Graf L, Toth M: Trypsinogen stabilization by mutation Arg117 $\rightarrow$ His: A unifying pathomechanism for hereditary pancreatitis? Biochem Biophys Res Commun 1999; 264: 505-508.

40 Chen JM, Raguenes O, Ferec C, Deprez PH, Verellen-Dumoulin C: A CGC > CAT gene conversion-like event resulting in the R122H mutation in the cationic trypsinogen gene and its implication in the genotyping of pancreatitis. J Med Genet 2000; (in press).

41 Chen JM, Ferec C: Origin and implication of the hereditary pancreatitis-associated N21I mutation in the cationic trypsinogen gene. Hum Genet 2000; 106: 125-126. 
42 Chen JM, Mercier B, Ferec C: Strong evidence that the N21I substitution in the cationic trypsinogen gene causes disease in hereditary pancreatitis. Gut 1999; 45: 916.

43 Sahin-Toth M: Hereditary pancreatitis-associated mutation asn (21) $\rightarrow$ ile stabilizes rat trypsinogen in vitro. J Biol Chem 1999; 274: 29699-29704.

44 Keim V, Albrecht H, Thorsten K, Niels T, Joachim M: Trypsinogen variant $\mathrm{N} 21 \mathrm{l}$ in hereditary pancreatitis is characterized by a higher stability in acidic environment but not by increased resistance to autolysis [Abstract]. Gastroenterology 1999; 116: A1137.

45 Raguenes $\mathrm{O}$, Deprez $\mathrm{P}$, Verellen $\mathrm{Ch}$ et al: Mutational screening of the cationic trypsinogen gene in a large cohort of patients with sporadic chronic pancreatitis reveals novel DNA variants [Abstract]. Am J Hum Genet 1999; 65: A486.

46 Chen JM, Raguenes O, Ferec C, Deprez PH, Verellen-Dumoulin C, Andriulli A: The A16V signal peptide cleavage site mutation in the cationic gene and chronic pancreatitis. Gastroenterology 1999; 117: 1508-1509.

47 Lerch MM, Neoptolemos JP: Maternal inheritance pattern of hereditary pancreatitis in patients with pancreatic carcinoma. J Natl Cancer Inst 1999; 91: 1590A-1591.

48 Roach JC, Wang K, Gan L, Hood L: The molecular evolution of the vertebrate trypsinogens. J Mol Evol 1997; 45: 640-652.

49 Sarles H, Camarena J, Bernard JP, Sahel J, Laugier R: Two forms of hereditary chronic pancreatitis. Pancreas 1996; 12: 138-141.
50 Bartness MA, Duerr RH, Ford MA et al: A new hereditary pancreatitis gene may map to chromosome 12 [Abstract]. Pancreas 1998; 17: 426.

51 Chen JM, Audrezet MP, Mercier B, Quere I, Ferec C: Exclusion of anionic trypsinogen and mesotrypsinogen involvement in hereditary pancreatitis without cationic trypsinogen gene mutations. Scand J Gastroenterol 1999; 34: 831-832.

52 Chen JM, Mercier B, Audrezet MP, Ferec C: Mutational analysis of the human pancreatic secretory trypsin inhibitor (PSTI) gene in hereditary and sporadic chronic pancreatitis. J Med Genet 2000; 37: 67-69.

53 Keim V, Hoffmeister A, Teich $\mathrm{N}$ et al: The pancreatitis-associated protein in hereditary and chronic alcoholic pancreatitis. Pancreas 1999; 19: 248-254.

54 Ravnik-Glavac M, Glavac D, di Sant' Agnese P, Chernick M, Dean $M$ : Cystic fibrosis gene mutations detected in hereditary pancreatitis. Pflugers Arch 1996; 431: R191-192.

55 Sharer N, Schwarz M, Malone G et al: Mutations of the cystic fibrosis gene in patients with chronic pancreatitis. N Engl J Med 1998; 339: 645-652.

56 Cohn JA, Friedman KJ, Noone PG, Knowles MR, Silverman LM, Jowell PS: Relation between mutations of the cystic fibrosis gene and idiopathic pancreatitis. N Engl J Med 1998; 339: 653-658.

57 Durie PR: Pancreatitis and mutations of the cystic fibrosis gene. N Engl J Med 1998; 339: 687-688. 